\title{
Biosynthesis of silver nanoparticles using stem bark extracts of Diospyros montana and their antioxidant and antibacterial activities
}

\author{
Devaraj Bharathi $^{1,3} \cdot$ M. Diviya Josebin ${ }^{2} \cdot$ Seerangaraj Vasantharaj $^{3} \cdot$ V. Bhuvaneshwari $^{1}$
}

Received: 25 December 2017 / Accepted: 6 February 2018 / Published online: 16 February 2018

(c) The Author(s) 2018. This article is an open access publication

\begin{abstract}
The present study reports an eco-friendly, biosynthesis of silver nanoparticles (AgNPs) using stem bark extract of Diospyros montana. Initially, the synthesis of AgNPs was confirmed by visual observation as color change. Further, the morphology of the biosynthesized nanoparticles, average size and presence of elemental silver were characterized by UV-Visible spectroscopy, scanning electron microscopy, transmission electron microscopy, energy dispersive X-ray and dynamic light scattering spectrometer. Qualitative phytochemical screening and FTIR spectral peaks supported the role of phytochemicals in bark extract for the metal reduction, stabilization and capping of silver nanoparticles. XRD studies demonstrated that crystalline nature and their average size of nanoparticles was $28 \mathrm{~nm}$ as determined by Scherrer's formula. The antioxidant ability of AgNPs and plant extract was analyzed using DPPH and Hydrogen peroxide assay. The percentage of DPPH and $\mathrm{H}_{2} \mathrm{O}_{2}$ activity was increased with increasing concentration of AgNPs. In vitro antibacterial effect of various concentration of AgNPs was investigated against both Gram positive (B.subtilis and S.aureus) and Gram negative (E.coli and K.aerogenes) bacterial strains. The result shows that biosynthesized AgNPs have significant antibacterial activity.
\end{abstract}

V. Bhuvaneshwari

bhuvana_bt@yahoo.co.in; bharathi.deva@yahoo.in

$1 \quad$ PG and Research Department of Biotechnology, Kongunadu Arts and Science College, Coimbatore, Tamilnadu, India

2 Bio Pharmacy Lab, Department of Microbial Biotechnology, Bharathiar University, Coimbatore, Tamilnadu, India

3 PG and Research Department of Biotechnology, Hindusthan College of Arts and Science, Coimbatore, Tamilnadu, India 


\section{Graphical abstract}

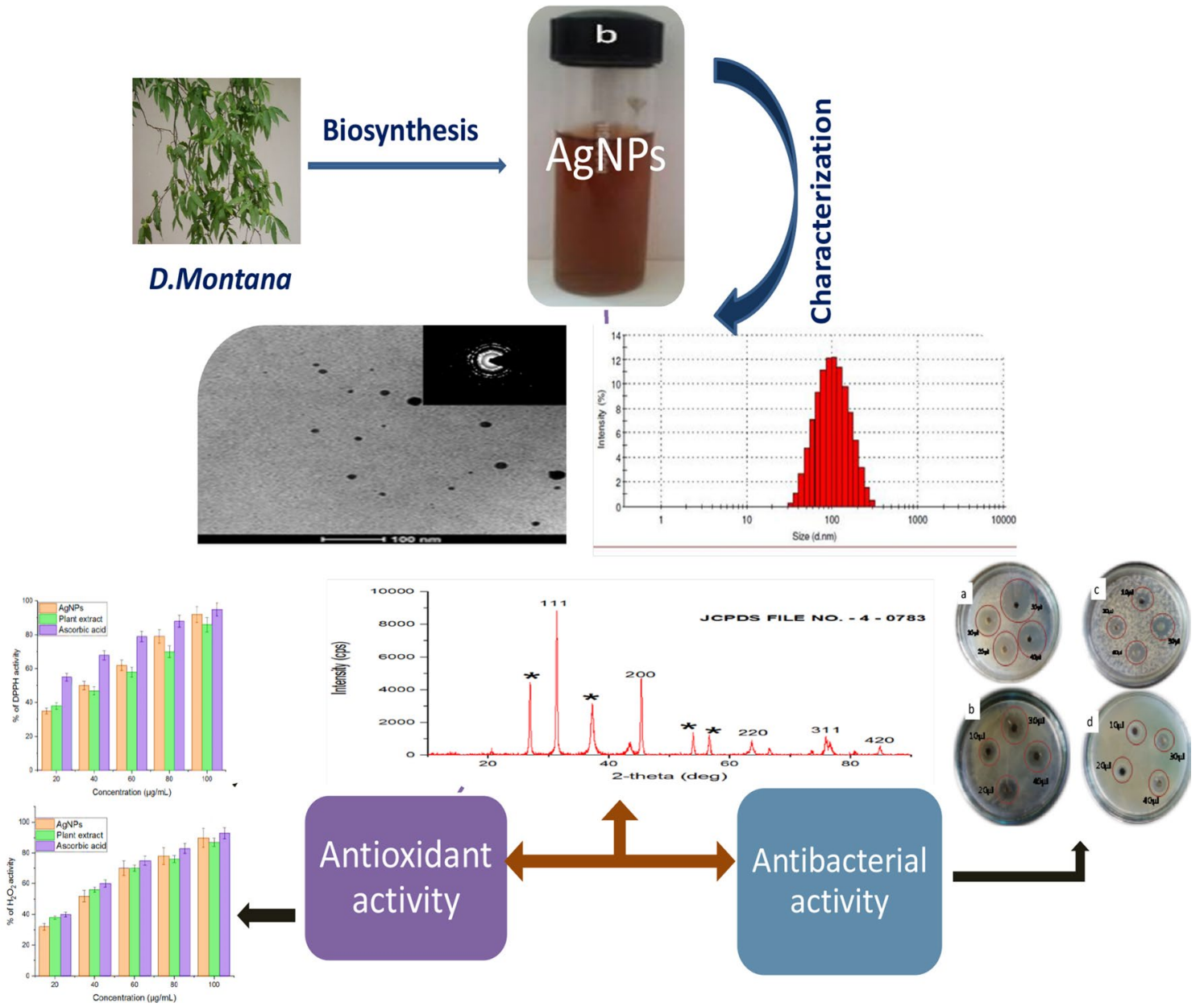

Keywords Diospyros montana $\cdot$ Silver nanoparticles $\cdot$ TEM $\cdot$ XRD $\cdot$ Antioxidant $\cdot$ Antibacterial activity

\section{Introduction}

Nanoscience is emerging as a fast growing area with tremendous application in biomedical science and technology. Nowadays, metal nanoparticles of silver, gold and platinum have been the subject of focused research area due to their unique optical, mechanical and chemical properties that are different from those large materials [1]. Among these metal nanoparticles, silver has become a focus of interest because they play a significant role in textile and pharmaceutical industries [2].

A number of approaches are available for the synthesis of silver nanoparticles (AgNPs) using electrochemical [3], microwave assists process [4], sono-chemical [5], radiation assist [6], reverse micelles process [7], phase transfer process [8] and photochemical synthesis [9]. Most of these methods are very expensive and also uses toxic chemicals which may lead to potential environmental and health risks [10]. In current scenario, metal nanoparticles protected by bio-organic ligands have attracted much interest due to their different applications [11].

In recent years, phytocompounds-facilitated synthesis of AgNPs is gaining significance due to their availability and eco-friendly [12]. Biosynthesis of silver nanoparticles using plants such as Eucalyptus chapmaniana [13], Momordica charantia [14], Terminalia bellirica [15], Cochlospermum religiosum [16], Eucalyptus chapmaniana [13] and many more plants has been reported. Silver nanoparticles have numerous applications such as bio-labeling, combating of microbes, detection of cancer, drug delivery and other diseases [17]. Antimicrobial activity of green synthesized nanoparticles allows them to use in water filtration process, textiles and food industries [18]. 
Diospyros montana also known as Bombay ebony and belong to the family of Ebanaceae. Diospyros genus is receiving increased attention as it is used in Indian traditional medicines like Ayurveda and Unani [19]. Diospyros montana is mainly distributed in Western Ghats of India, Sri Lanka and Australia. It was reported that genus Diosyros contain various phytochemicals such as phenols, flavonoids, saponins, terpinoids and reducing sugars [20]. Diospyros montana has significant pharmacological activities, used in the treatment of cough, ulcer, anti-hypersensitive and snake bites [21, 22]. Bark extract of D.montana contains diospyrin compound, which acts as a tumor inhibitory agent [23]. However, to date, less attention has been paid to synthesis nanoparticles from this plant. To the best of our knowledge, this is the first report on biosynthesis of AgNPs from stem bark extract of D.montana. We have demonstrated the phytochemical screening of methanolic stem bark extract, biosynthesis, characterization of silver nanoparticles and their free radical scavenging and antibacterial activities.

\section{Materials and methods}

\section{Chemicals and reagents}

Silver nitrate $\left(\mathrm{AgNO}_{3}\right)$, methanol, 2,2-diphenyl-1-picrylhydrazyl (DPPH), ascorbic acid was purchased from Sigma Aldrich. All other reagents and chemicals used in this research were of analytical grade.

\section{Bacterial source}

Bacterial strains Escherichia coli (MTCC 443), Klebsiella aerogenes (MTCC 98), Bacillus subtilis (MTCC 441) and Staphylococcus aureus (MTCC 3160) were used and maintained in nutrient agar (Himedia, Mumbai) slants at $4{ }^{\circ} \mathrm{C}$.

\section{Plant collection and authentication}

The stem barks of D.montana were collected from Wayanad District (Western Ghats), Kerala, India. It was identified and authenticated (Ref. BSI/SRC/21/12/2015/Tech/1219) at Botanical Survey of India, Coimbatore, India.

\section{Preparation of methanolic stem bark extract}

The stem barks were washed thoroughly thrice with distilled water and dried for 7 days. The fine powder was obtained from stem bark using kitchen blender. About $25 \mathrm{~g}$ of stem bark dry powder was extracted with $250 \mathrm{ml}$ of methanol solvent using soxhlet extractor. After completion of the extraction, the methanol solvents were evaporated using rotatory evaporator. Prepared extract was concentrated, dried and kept at $4{ }^{\circ} \mathrm{C}$ until further use.

\section{Qualitative phytochemical screening}

Phytochemical screening of stem bark extract of D.montana was performed for the qualitative detection of different phytocompounds such as alkaloids, flavonoids, saponins, glycosides, phenols, steroids, carbohydrates, oils and fats, proteins, amino acids, tannins, gums and reducing sugars. All phytochemical tests were performed according to the standard methods described by Al-Owaisi [24] and Sheel [25].

\section{Biosynthesis of silver nanoparticles}

Silver nitrate solution ( $1 \mathrm{mM}$ ) was prepared in amber bottle and stored at dark place. The prepared stem bark extract was mixed with $1 \mathrm{mM} \mathrm{AgNO}_{3}$ solution in 1:9 proportions and kept at room temperature for $30 \mathrm{~min}$. Purified AgNPs from the samples were obtained by centrifuging the solution at $10,000 \mathrm{rpm}$ for $20 \mathrm{~min}$. The precipitate was re-dispensed with $10 \mathrm{ml}$ double distilled water and again centrifuged at $10,000 \mathrm{rpm}$ for $10 \mathrm{~min}$ for removing excess biomass. The pellet of Ag nanoparticles was collected carefully and dried in desiccators for $12 \mathrm{~h}$. The dried powder of AgNPs was used for further test.

\section{Characterization of AgNPs}

\section{UV-Visible spectroscopy}

The formation of nanoparticles was preliminarily confirmed by visual observation as color change from watery to brown color. Further, the reduction of Ag ions in the solution mixture was confirmed by UV-Visible spectroscopy (JASCO UV-Vis NIR V-670). The spectral data of synthesized AgNPs were recorded from 200 to $600 \mathrm{~nm}$ at a resolution of $2 \mathrm{~nm}$.

\section{SEM and EDX}

The morphology of AgNPs was determined by SEM (Hitachi S -340 N). SEM samples were prepared on a carbon coated copper grid by placing a small amount of AgNPs on the SEM grid, excess samples was cleaned by blotting paper and then samples were allowed to dry under mercury lamp. This experiment was conducted at an accelerator voltage of $20 \mathrm{kV}$. Energy dispersive X-ray analysis was also taken on the same instrument. 


\section{TEM}

Transmission electron microscope (TEM) (JEOL JEM-2100) analysis was conducted by drop coating of Ag nanoparticles on a copper grid and operated at an accelerated voltage at $80 \mathrm{kV}$. The grid was dried for $2 \mathrm{~h}$ and imaged.

\section{DLS particle size analysis}

Average size and polydispersity index of deionised waterdiluted silver nanoparticles were measured by dynamic light scattering spectroscopy (DLS) (Malvern-zeta analyser) operated with a $\mathrm{He}-\mathrm{Ne}$ laser.

\section{XRD analysis}

The structure of the AgNPs was determined using XRD technique. For X-ray diffraction studies (XRD), dried silver nanoparticles were coated on XRD grid (XPERT-PRO) and diffraction recorded in the $2 \theta$ range from $10^{\circ}$ to $90^{\circ}$. The spectral data were operated at $40 \mathrm{kV}$ and a current of $40 \mathrm{~mA}$.

\section{FT-IR}

The biologically active components that are responsible for silver reduction, formation and capping were identified using Fourier Transform Infra-Red (FTIR) spectroscopy (Nicolet is 5, Thermo Scientific) by $\mathrm{KBr}$ pellet method. FTIR spectral reading was carried out in the range from 500 to $4000 \mathrm{~cm}^{-1}$ at a resolution of $4 \mathrm{~cm}^{-1}$.

\section{Antioxidant activity}

\section{DPPH and $\mathrm{H}_{2} \mathrm{O}_{2}$ free radical scavenging activity}

The DPPH free radical scavenging activity of synthesized nanoparticles and plant extract were carried out spectrophotometrically $(517 \mathrm{~nm})$ according to the method reported by Govindappa [26]. The Hydrogen peroxide assay, a method for measuring free radical scavenging activity, was assessed spectrophotometrically (230 nm) according to Yadav [27]. Antioxidant activity was noted in terms of stranded control ascorbic acid antioxidant equivalents. Percentage of the activity was calculated using the following equation; Percentage of antioxidant activity $=[(a-b) / a] \times 100$, where $a$ was the absorbance of the control (blank) and $b$ was the absorbance of samples.

\section{Antibacterial activity}

The antibacterial activity of AgNPs were carried out by agar well diffusion method described by Gudikandula [28] against Gram negative bacteria such as E.coli (MTCC 443) and K.aerogenes (MTCC 98), Gram positive bacteria such as B.subtilis (MTCC 441) and S.aureus (MTCC 3160). Muller-Hinton Agar (Himedia, Mumbai) plates were prepared, sterilized and solidified. Each bacterial strain $\left(1 \times 10^{5} \mathrm{CFU} /\right.$ $\mathrm{mL}$ ) was swabbed uniformly on the prepared individual petri plates using sterile cotton swabs. Four wells of size approximately $6 \mathrm{~mm}$ are made on prepared plates using gel puncture. Different concentration of AgNPs (10, 20, 30 and $40 \mu \mathrm{L}$ ) was loaded into the wells of all plates. After incubation for $24 \mathrm{~h}$ at $37^{\circ} \mathrm{C}$, the plates were examined for zone of incubation in $\mathrm{mm}$.

\section{Statistical analysis}

All the experiments were carried out in triplicates and the results were expressed as mean \pm standard deviation. Statistical analysis was done using origin software (Origin pro evaluation, 2018).

\section{Results and discussion}

\section{Qualitative phytochemical screening}

The results of qualitative phytochemical screening of methanolic stem bark extract of D.montana are shown in Table 1 . Phytochemical screening showed the presence of saponins, alkaloids, glycosides, phenols, steroids, flavonoids and tannins. It was reported that the leaves of D.montana contain steroids, phenols, flavonoids, saponins, terpenoids [19]. The presence of these biologically active compounds may play a significant role in formation, capping and stabilization of AgNPs [29].

Table 1 Phytochemical screening of methanolic stem bark extract of D.montana

\begin{tabular}{lll}
\hline S. no. & Phytochemicals & $\begin{array}{l}\text { Methanolic } \\
\text { stem bark } \\
\text { extract }\end{array}$ \\
\hline 1 & Alkaloids & + \\
2 & Saponins & + \\
3 & Flavonoids & + \\
4 & Glycosides & + \\
5 & Phenols & + \\
6 & Steroids & + \\
7 & Oils and fates & + \\
8 & Proteins and amino acids & + \\
9 & Carbohydrates & + \\
10 & Tannins & - \\
11 & Gums & - \\
12 & Reducing sugars & + \\
\hline
\end{tabular}

+ sign denotes positive and - sign denotes negative 


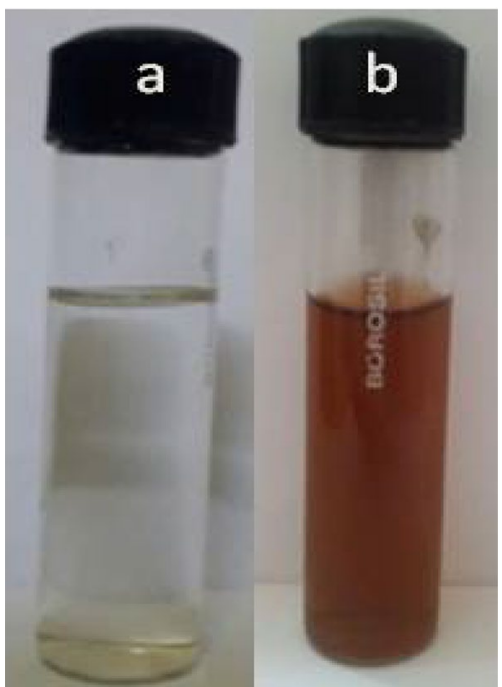

Fig. 1 Biosynthesis of AgNPs using D.montana: a stem bark extract of D.montana and b AgNPs

\section{Biosynthesis of AgNPs using D.Montana}

For the biosynthesis, bark extract was mixed in the aqueous solution of $\mathrm{AgNO}_{3}$ at room temperature. Initially, the color changed from watery to brown color (Fig. 1) within 30 min after which no color change was observed. The turn in color from watery to brown color indicates the formation of AgNPs and this change may be due to the SPR (Surface Plasmon Resonance) of AgNPs in the reaction samples [30, 31].

\section{Characterization of AgNPs}

The formation of silver nanoparticles was measured using UV-Visible Spectroscopy from 200 to $600 \mathrm{~nm}$ wavelength range and the highest spectral peak was observed at $432 \mathrm{~nm}$ (Fig. 2). It was reported earlier that the absorbance around $432 \mathrm{~nm}$ for Ag is a characteristic feature of metal nanoparticles [32].

SEM image (Fig. 3) showed the morphology of AgNPs is predominantly spherical shape with aggregation. TEM images showed that the size of individual AgNPs ranged from 5 to $40 \mathrm{~nm}$. The morphology of Ag nanoparticles was also spherical (Fig. 4). Similar to our study, Krishnaraj [33] synthesized the silver nanoparticles from Bacoba monnieri extract and they obtained varying size and morphology of the silver nanoparticles ranged between 2 and $50 \mathrm{~nm}$ from TEM analysis. SAED (selected area electron diffraction) pattern of synthesized nanoparticles was also shown in the inset of Fig. 4. In this pattern, a circular ring was observed. This was due to the crystalline nature of silver nanoparticles.

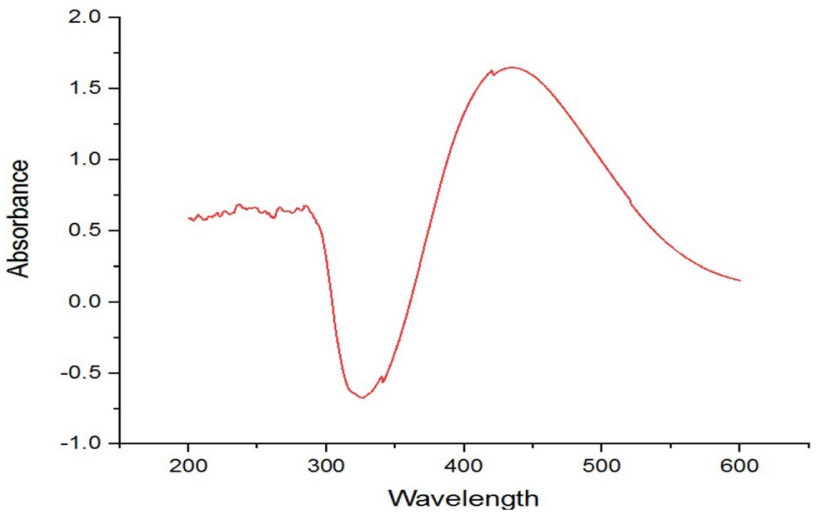

Fig. 2 UV-Visible spectrum of synthesized AgNPs

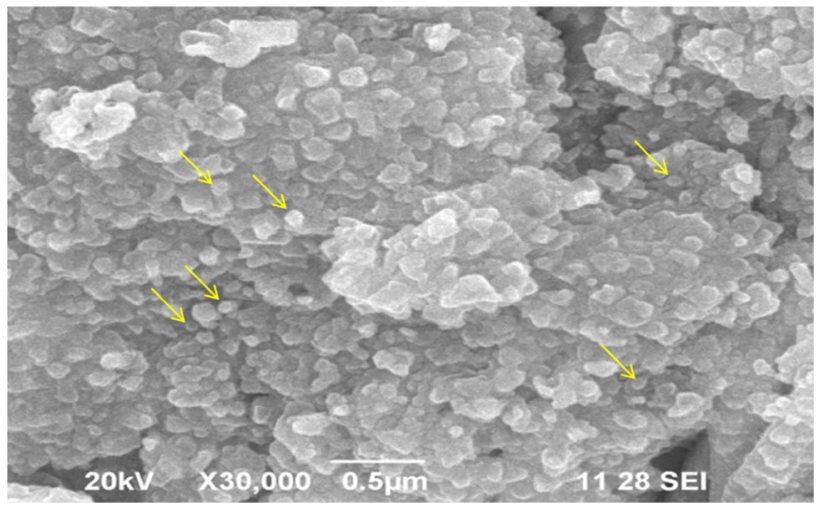

Fig. 3 SEM image of silver nanoparticles

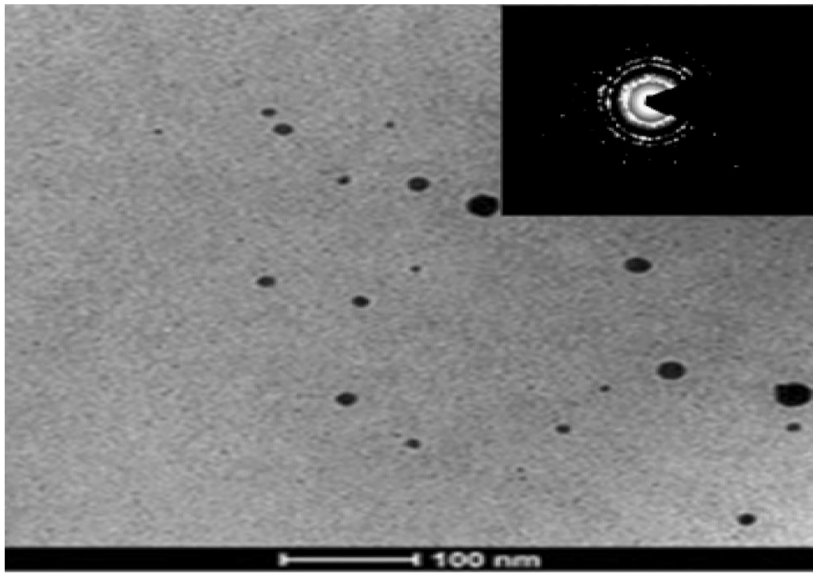

Fig. 4 TEM image of silver nanoparticles and insets show the SEAD pattern

EDX spectrum from Fig. 5 represents signal from $\mathrm{Ag}$ $(0.3$ and $3 \mathrm{keV})$ together with $\mathrm{O}(0.5 \mathrm{keV})$. The spectrum at $3 \mathrm{keV}$ indicates that the $\mathrm{Ag}$ has been correctly identified. Generally, Ag nanoparticles show typical optical peak at 
Fig. 5 EDX spectrum of silver nanoparticles

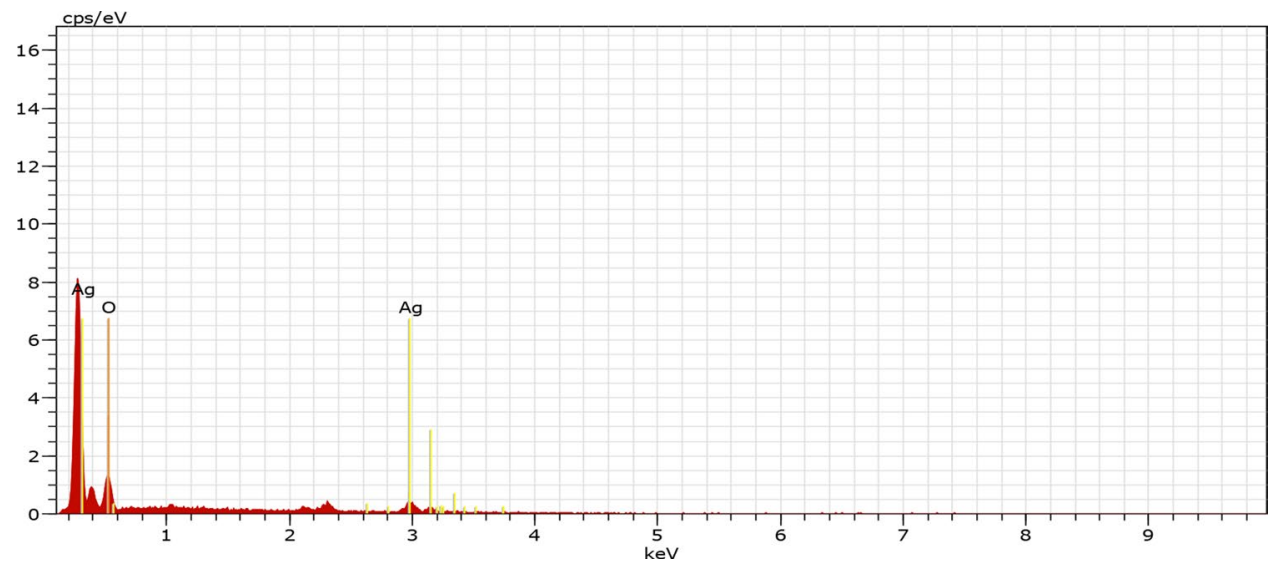

Fig. 6 DLS analysis of synthesized silver nanoparticles
Z-Average (d.nm): 86.84
Pdl: 0.231
Intercept: 0.921
It qually : Good
Result quality : Good

Size (d.nm):

$\%$ Intensity

Width (d.n...

100.0

49.10

Peak 2: $\quad 0.000$

0.0

0.000

Peak 3: $\quad 0.000$

0.0

0.000

Size Distribution by Intensity

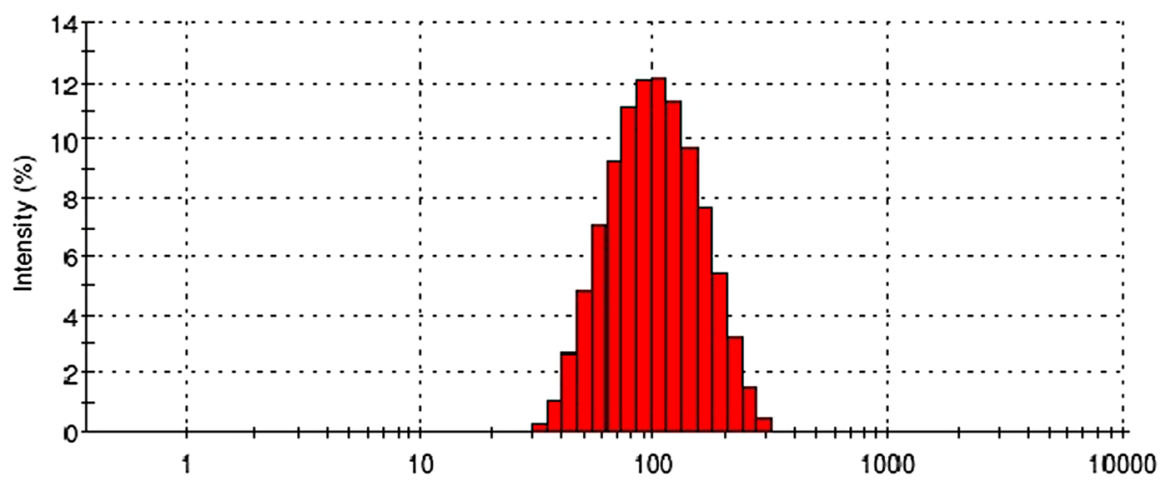

$3 \mathrm{keV}$ [34]. The absorption peak of O in EDX spectrum might be due to the involvement of phytocompounds in capping and stabilizing of $\mathrm{Ag}$ nanoparticles through $\mathrm{O}$ related groups [14, 15].

The size distribution histogram of DLS revealed the $Z$ average diameter of $86.84 \mathrm{~nm}$ with polydispersity $(0.231)$ for synthesized AgNPs (Fig. 6). This is quite larger than the size reported by TEM and the variation mainly due to the process involved in sample preparation [35]. The polydispersity index values are less than 0.7 indicating the quality of nanoparticles to be good [36].

The XRD patterns shown in Fig. 7 demonstrate the crystalline nature of synthesized AgNPs. Highest $2 \theta$ diffraction

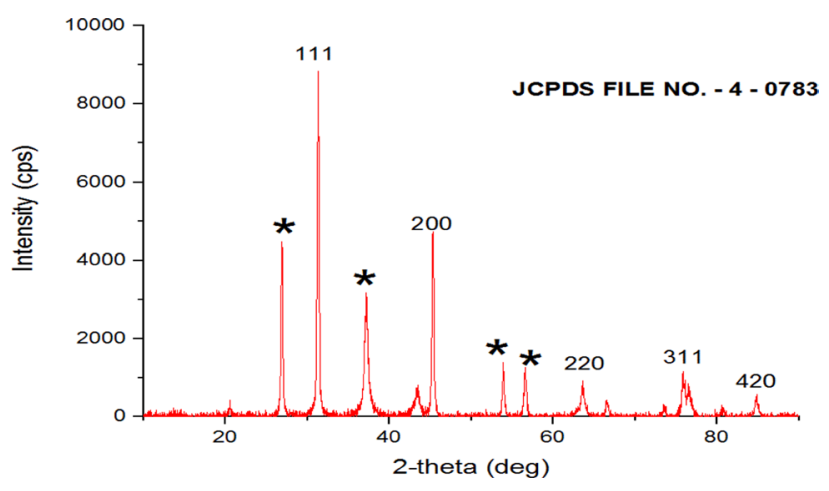

Fig. 7 XRD pattern of Ag nanoparticles 
peaks observed at $37.4^{\circ}, 46.1^{\circ}, 64.2^{\circ}, 78.1^{\circ}$ and $85.2^{\circ}$ which corresponding to (111), (200), (220), (311) and (420) planes, respectively $[15,33]$, which confirms the face-centered cubic structure of synthesized nanoparticles [32]. Corresponding planes were matched with JCPDS, File No. 4-0783 (Joint Committee on Powder Diffraction Standards) values for silver. The average mean size of biosynthesized nanoparticles was determined using Debye-Scherrer's formula, $D=0.9 \lambda / \beta \cos \theta$ and is estimated to be approximately $28 \mathrm{~nm}$ from the breadth of the reflection. Where $\lambda$ is the wavelength of $\mathrm{X}$-rays used, $\beta$ is the broadening of diffraction line used measured at half maximum intensity and $\theta$ is Bragg's diffraction angle. The extra diffraction peaks $(*)$ in the XRD pattern may be due to the crystallization of bio-organic phase in the plant extract [28].

FTIR spectra in Fig. 8 indicated the presence of phytochemicals which may be responsible for the synthesis of AgNPs from D.montana. The highest peak at 3364.92, 2978.32 and $1080.30 \mathrm{~cm}^{-1}$ attributed to $\mathrm{N}-\mathrm{H}$ stretch, $\mathrm{C}-\mathrm{H}$ stretch vibration of amides, alkanes and aliphatic amines. The medium bands at 3616.26, 2940.05, and $1099.58 \mathrm{~cm}^{-1}$ corresponded to $\mathrm{O}-\mathrm{H}$ stretch and $\mathrm{C}-\mathrm{H}$ stretch possible of alcohol, phenols and amines. The other peaks at 2396.10, $1581.48,1462.08$ and $853.15 \mathrm{~cm}^{-1}$ were assigned to the presence of aldehydes $(\mathrm{H}-\mathrm{C}=\mathrm{O}, \mathrm{C}-\mathrm{H})$, nitrogen $(\mathrm{N}-\mathrm{O})$ and aromatic compounds $(\mathrm{C}-\mathrm{H})$, respectively $[16,35]$. This spectroscopic study confirmed the presence of amides, phenol, nitrogen and aromatic compounds has a strong binding affinity with $\mathrm{Ag}$ and also plays a significant role in reducing and capping of $\mathrm{Ag}$ ions for the conversion of $\mathrm{Ag}^{+}$into AgNPs [37].

Fig. 8 FTIR analysis of biosynthesized AgNPs

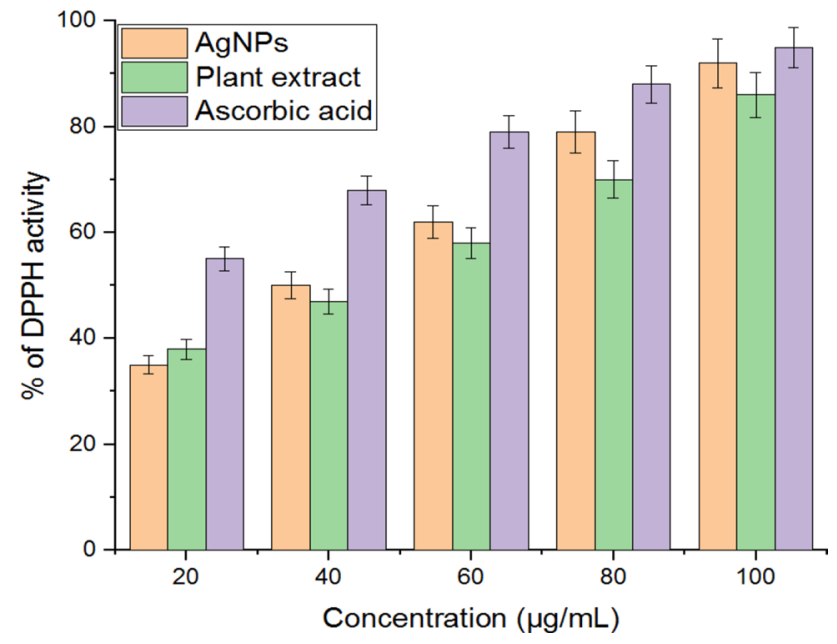

Fig. 9 DPPH antioxidant activity of AgNPs and stem bark extract of D.montana

\section{Antioxidant activity}

The free radical scavenging ability of biosynthesized AgNPs and plant extract was determined using DPPH and $\mathrm{H}_{2} \mathrm{O}_{2}$ assay. In DPPH assay, the antioxidant activity of AgNPs and plant extract improved as the concentration of samples used for assay was increased from 20 to $100 \mu \mathrm{g} /$ $\mathrm{mL}$ (Fig. 9). It was observed that free radical scavenging activity of AgNPs and bark extract of D.monanta increased in a concentration-dependent manner. In addition, the antioxidant potential of biosynthesized Ag nanoparticles was significant to plant extract and similar to standard (ascorbic acid) control.

$\mathrm{H}_{2} \mathrm{O}_{2}$ assay is a photometric test for the determination of hydrogen peroxide in biological fluids. $\mathrm{In}_{2} \mathrm{O}_{2}$ assay,

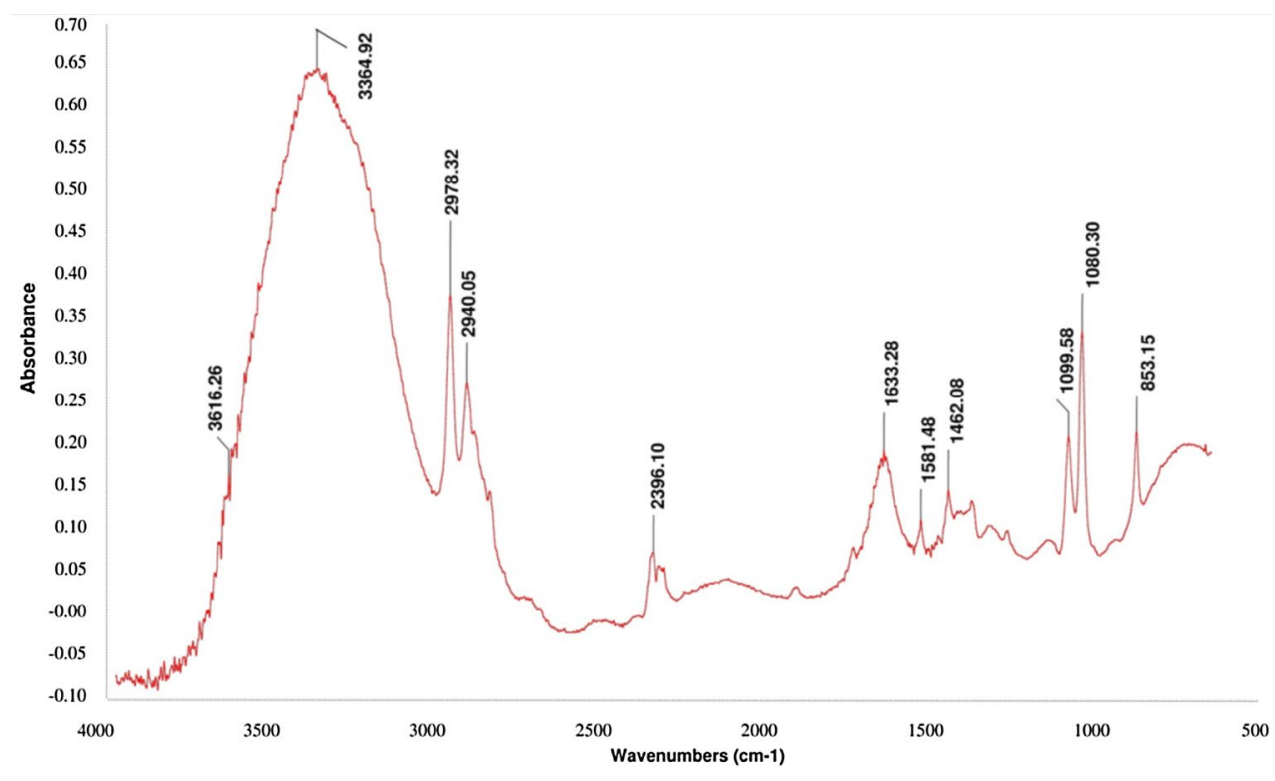




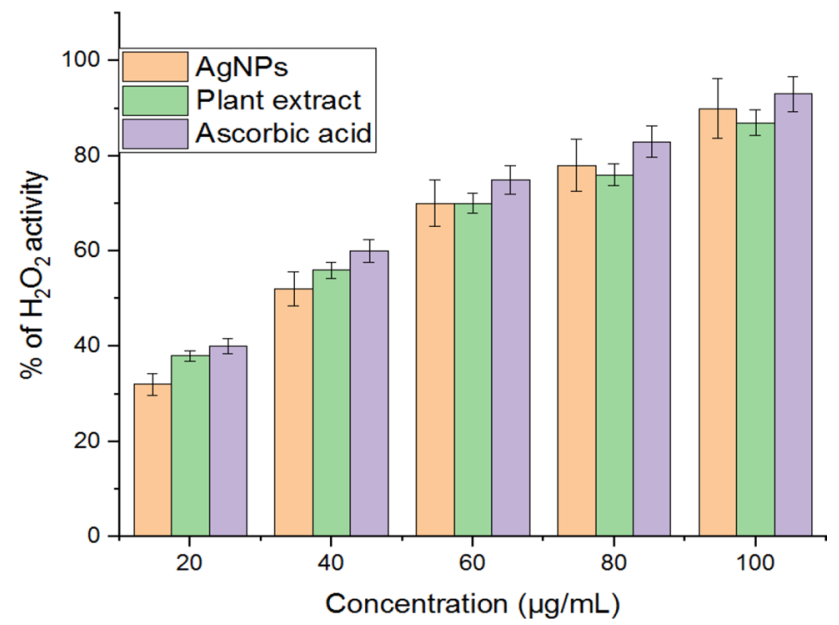

Fig. $10 \mathrm{H}_{2} \mathrm{O}_{2}$ antioxidant activity of synthesized AgNPs and stem bark extract of D.montana

silver nanoparticles showed equal potency of activity compared to methanolic stem bark extract of plant (Fig. 10). The free radical scavenging activity might be due to the presence of phyto compounds, especially phenols that have the ability to donate the hydrogen atoms in their $\mathrm{OH}$ groups [38]. Antioxidant results indicated that there was increase in free radical scavenging activity of AgNPs in a concentration-dependent manner.

\section{Antibacterial activity}

The synthesized AgNPs showed significant antibacterial activity against both Gram positive and Gram negative bacteria. The antibacterial effect of different concentration of $\operatorname{AgNPs}(10,20,30$ and $40 \mu \mathrm{L})$ was shown in Fig. 11 . The highest anti-bacterial zone of inhibition was recorded in K.aerogenes followed by E.coli, B.subtilis and S.aureus (Fig. 12). From this study, AgNPs showed high zone of inhibition against Gram negative bacterial strains compared with Gram positive bacteria. This may be due to the presence of thin peptidoglycan layer in the Gram negative bacteria but in case of Gram positive bacteria, which are made up of thick peptidoglycan layer [39]. It was also reported that the charged AgNPs have the ability to bind negatively charged Gram negative bacterial cell wall better on contrary [19].

\section{Conclusions}

In this study, we have synthesized AgNPs by eco-friendly and cost effective method using D.montana stem bark extract. The phytochemicals present in the stem bark extract of plant act as a strong reducing and capping agents for the formation of AgNPs. The morphology and size of the silver nanoparticles were characterized by UV-Visible spectroscopy, SEM, TEM, EDX and DLS. XRD reports revealed that
Fig. 11 Antibacterial activity of AgNPs against a K.aerogenes $\mathbf{b}$ E.coli c B.subtilis d S.aureus
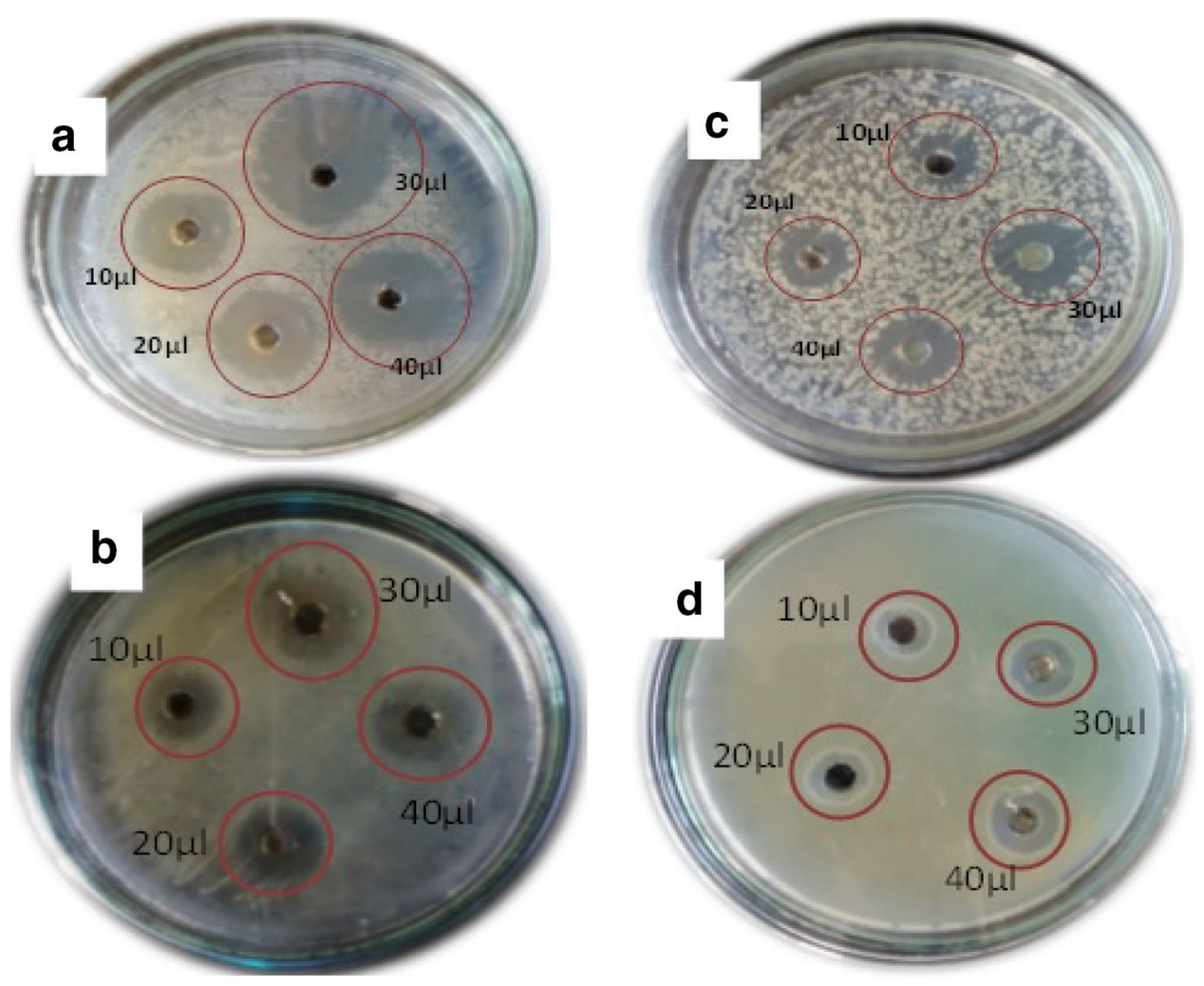


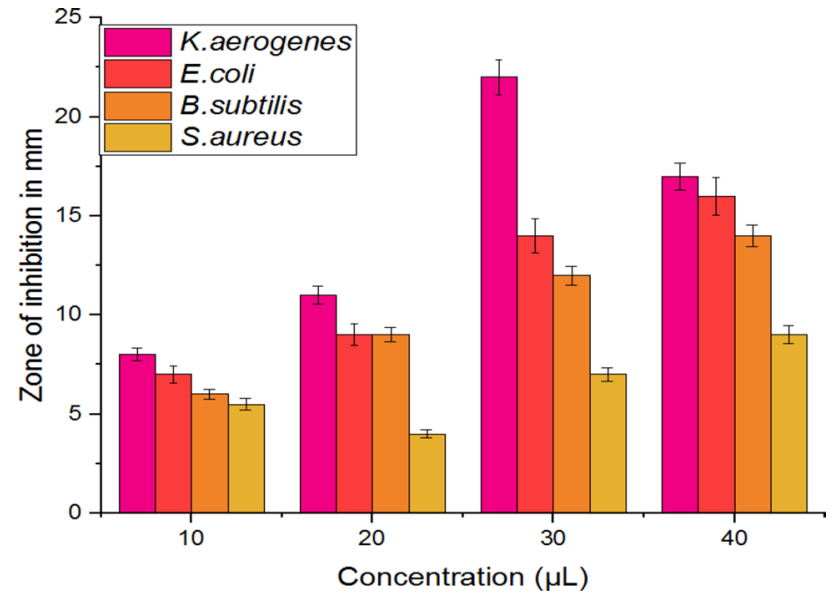

Fig. 12 Zone of inhibition of silver nanoparticles against Gram positive and Gram negative bacteria via agar well diffusion method

synthesized silver nanoparticles were crystalline in nature with average mean size as $28 \mathrm{~nm}$ and FTIR studies supported the confirmation of bioactive compounds for the $\mathrm{Ag}^{+}$reduction. Biosynthesized AgNPs showed significant antibacterial activity against Gram negative bacteria compared to Gram positive bacteria and also exhibit remarkable free radical scavenging activity. Further studies on AgNPs will be carried out for pharmacological applications.

Acknowledgement The authors like to thank DST-FIST for providing the laboratory facilities and we acknowledge the Department of Nanoscience and Technology, Bharathiar University, Coimbatore and Anna University for extending their nanoparticles characterization facilities established under the DST-PURSE Program.

\section{Compliance with ethical standards}

Conflict of interest The authors have declared no conflict of interest.

Open Access This article is distributed under the terms of the Creative Commons Attribution 4.0 International License (http://creativeco mmons.org/licenses/by/4.0/), which permits unrestricted use, distribution, and reproduction in any medium, provided you give appropriate credit to the original author(s) and the source, provide a link to the Creative Commons license, and indicate if changes were made.

\section{References}

1. Dauthal, P., Mukhopadhyay, M.: In-vitro free radical scavenging activity of biosynthesized gold and silver nanoparticles using Prunus armeniaca (apricot) fruit extract. J. Nanopart. Res. 15, $1366(2013)$

2. Mie, R., Samsudin, M.W., Din, L.B.: Synthesis of silver nanoparticles with antibacterial activity using the lichen Parmotrema praesorediosum. Int. J. Nanomed. 9, 121 (2014)

3. Starowicz, M., Stypuła, B., Banaś, J.: Electrochemical synthesis of silver nanoparticles. Electrochem. Commun. 8, 227-230 (2006)
4. Siamaki, A.R., Abd El Rahman, S.K., Abdelsayed, V., El-Shall, M.S., Gupton, B.F.: Microwave-assisted synthesis of palladium nanoparticles supported on graphene: a highly active and recyclable catalyst for carbon-carbon cross-coupling reactions. J. Catal. 279, 1-11 (2011)

5. Talebi, J., Halladj, R., Askari, S.: Sonochemical synthesis of silver nanoparticles in Y-zeolite substrate. J. Mater. Sci. 45, 3318-3324 (2010)

6. Temgire, M.K., Joshi, S.S.: Optical and structural studies of silver nanoparticles. Radiat. Phys. Chem. 71, 1039-1044 (2004)

7. Bae, D.S., Kim, E.J., Bang, J.H., Kim, S.W., Han, K.S., Lee, J.K., Adair, J.H.: Synthesis and characterization of silver nanoparticles by a reverse micelle process. Met. Mater. Int. 11, 291-294 (2005)

8. Ankamwar, B., Damle, C., Ahmad, A., Sastry, M.: Biosynthesis of gold and silver nanoparticles using Emblica officinalis fruit extract, their phase transfer and transmetallation in an organic solution. J. Nanosci. Nanotechnol. 5, 1665-1671 (2005)

9. Jin, R., Cao, Y., Mirkin, C.A., Kelly, K.L., Schatz, G.C., Zheng, J.G.: Photo induced conversion of silver nanospheres to nanoprisms. Science 294, 1901-1903 (2001)

10. Ponarulselvam, S., Panneerselvam, C.: Synthesis of silver nanoparticles using leaves of Catharanthus roseus Linn. G. Don and their antiplasmodial activities. Asian Pac J Trop. Biomed. 2, 574-580 (2012)

11. Das, R., Gang, S., Nath, S.S.: Preparation and antibacterial activity of silver nanoparticles. J. Biomater. Nanobiotechnol. 2, 472-475 (2011)

12. Rout, Y., Behera, S., Ojha, A.K., Nayak, P.L.: Green synthesis of silver nanoparticles using Ocimum sanctum (Tulashi) and study of their antibacterial and antifungal activities. J. Microbiol. Antimicrob. 4, 103-109 (2012)

13. Sulaiman, G.M., Mohammed, W.H.: Green synthesis, antimicrobial and cytotoxic effects of silver nanoparticles using Eucalyptus chapmaniana leaves extract. Asian Pac. J. Trop. Biomed. 3, 58-63 (2013)

14. Ajitha, B., Reddy, Y.A.K., Reddy, P.S.: Biosynthesis of silver nanoparticles using Momordica charantia leaf broth: evaluation of their innate antimicrobial and catalytic activities. J. Photochem. Photobiol., B 146, 1-9 (2015)

15. Patil, S., Chaudhari, G., Paradeshi, J., Mahajan, R., Chaudhari, B.L.: Instant green synthesis of silver-based herbo-metallic colloidal nanosuspension in Terminalia bellirica fruit aqueous extract for catalytic and antibacterial applications. 3. Biotech. 7, 36 (2017)

16. Sasikala, A., Rao, M.L., Savithramma, N., Prasad, T.N.V.K.V.: Synthesis of silver nanoparticles from stem bark of Cochlospermum religiosum (L.) Alston: an important medicinal plant and evaluation of their antimicrobial efficacy. Appl. Nanosci. 5, 827-835 (2014)

17. Manivasagan P, Venkatesan J, Senthilkumar K, Sivakumar K, Kim SK (2013) Biosynthesis, antimicrobial and cytotoxic effect of silver nanoparticles using a novel Nocardiopsis sp. MBRC-1. Res. Biomed. 1-9

18. Van Dong, P., Ha, C.H., Kasbohm, J.: Chemical synthesis and antibacterial activity of novel-shaped silver nanoparticles. Int. Nano. Lett. 2, 9 (2012)

19. Ebbo, A.A., Mammam, M., Suleiman, M.M., Ahmed, A., Bello, A.: Preliminary phytochemical screening of Diospyros mespiliformis. Anat. Physiol. 4, 2161 (2014)

20. Kantamreddi, V.S., Wright, C.W.: Investigation of Indian Diospyros species for antiplasmodial properties. Evid. Based Complement. Altern. Med. 5, 187-190 (2008)

21. Kokila, K., Elavarasan, N., Sujatha, V.: Diospyros montana leaf extract-mediated synthesis of selenium nanoparticles and their biological applications. New J. Chem. 41, 7481-7490 (2017) 
22. Sarma, M.D., Ghosh, R., Patra, A., Hazra, B.: Synthesis and antiproliferative activity of some novel derivatives of diospyrin, a plant-derived naphthoquinonoid. Bioorganic Med. Chem. 15, 3672-3677 (2007)

23. Ravishankara, M.N., Shrivastava, N., Jayathirtha, M.G., Padh, H., Rajani, M.: Sensitive high-performance thin-layer chromatographic method for the estimation of diospyrin, a tumour inhibitory agent from the stem bark of Diospyros Montana Roxb. J. Chromatogr. B Biomed. Sci. Appl. 744, 257-262 (2000)

24. Al-Owaisi, M., Al-Hadiwi, N., Khan, S.A.: GC-MS analysis, determination of total phenolics, flavonoid content and free radical scavenging activities of various crude extracts of Moringa peregrina (Forssk.) Fiori leaves. Asian Pac. J Trop. Med. 4, 964-970 (2014)

25. Sheel, R., Nisha, K., Kumar, J.: Preliminary phytochemical screening of methanolic extract of Clerodendron infortunatum. IOSR J. Appl. Chem 7, 10-13 (2014)

26. Govindappa, M., Channabasava, R., Kumar, K.S., Pushpalatha, K.C.: Antioxidant activity and phytochemical screening of crude endophytes extracts of Tabebuia argentea Bur. \& K. Sch. Am. J Plant Sci. 4, 1641-1652 (2013)

27. Yadav, M., Yadav, A., Yadav, J.P.: In vitro antioxidant activity and total phenolic content of endophytic fungi isolated from Eugenia jambolana Lam. Asian Pac. J. Trop. Med. 7, S256-S261 (2014)

28. Gudikandula, K., Charya Maringanti, S.: Synthesis of silver nanoparticles by chemical and biological methods and their antimicrobial properties. J. Exp. Nanosci. 11, 714-721 (2016)

29. Oluwaniyi, O.O., Adegoke, H.I., Adesuji, E.T., Alabi, A.B., Bodede, S.O., Labulo, A.H., Oseghale, C.O.: Biosynthesis of silver nanoparticles using aqueous leaf extracts of Thevetia peruviana Juss and its antimicrobial activities. Appl. Nanosci. 6, 903-912 (2016)

30. Vanaja, M., Gnanajobitha, G., Paulkumar, K.: Phytosynthesis of silver nanoparticles by Cissus quadrangularis: influence of physicochemical factors. J. Nanostructure Chem. 3, 17 (2013)
31. Kumar, B., Smita, K., Cumbal, L., Debut, A.: Green synthesis of silver nanoparticles using Andean blackberry fruit extract. Saudi J. Biol. Sci. 24, 45-50 (2017)

32. Gopinath, K., Gowri, S., Arumugam, A.: Phytosynthesis of silver nanoparticles using Pterocarpus santalinus leaf extract and their antibacterial properties. J. nanostructure 3, 68 (2013)

33. Krishnaraj, C., Jagan, E.G., Ramachandran, R.: Effect of biologically synthesized silver nanoparticles on Bacopa monnieri (Linn.) Wettst. plant growth metabolism. Process Biochem. 47, 651-658 (2012)

34. Ibrahim, H.M.: Green synthesis and characterization of silver nanoparticles using banana peel extract and their antimicrobial activity against representative microorganisms. J. Radiat. Res. Appl. Sci. 8, 265-275 (2015)

35. Jamdagni, P., Khatri, P., Rana, J.S.: Green synthesis of zinc oxide nanoparticles using flower extract of Nyctanthes arbortristis and their antifungal activity. J. King Saud Univ. Sci. (2016)

36. Zia, F., Ghafoor, N., Iqbal, M., Mehboob, S.: Green synthesis and characterization of silver nanoparticles using Cydonia oblong seed extract. Appl. Nanosci. 6, 1023-1029 (2016)

37. Vasantharaj, S., Sripriya, N., Shanmugavel, M., Manikandan, E., Gnanamani, A., Senthilkumar, P.: Surface active gold nanoparticles biosynthesis by new approach for bionanocatalytic activity. J. Photochem. Photobiol. B 179, 119-125 (2018)

38. Sagbo, I.J., Afolayan, A.J., Bradley, G.: Antioxidant, antibacterial and phytochemical properties of two medicinal plants against the wound infecting bacteria. Asian Pac. J. Trop. Biomed. 7, 817-825 (2017)

39. Kokila, T., Ramesh, P.S., Geetha, D.: Biosynthesis of silver nanoparticles from Cavendish banana peel extract and its antibacterial and free radical scavenging assay: a novel biological approach. Appl. Nanosci. 5, 911-920 (2015)

Publisher's Note Springer Nature remains neutral with regard to urisdictional claims in published maps and institutional affiliations. 